\title{
Quantitative aspects of the metabolism of lignans in pigs fed fibre-enriched rye and wheat bread
}

\author{
Helle N. Lærke ${ }^{1}$, Marianne A. Mortensen ${ }^{1}$, Mette S. Hedemann ${ }^{1}$, Knud E. Bach Knudsen ${ }^{1}$, \\ José L. Penalvo ${ }^{2}$ and Herman Adlercreutz ${ }^{2}$ \\ ${ }^{1}$ Department of Animal Health, Faculty of Agricultural Sciences, Welfare and Nutrition, Aarhus University, PO Box 50, 8830 Tjele, \\ Denmark \\ ${ }^{2}$ Division of Clinical Chemistry and Institute for Preventive Medicine, Nutrition and Cancer, Folkhälsan Research Centre, \\ University of Helsinki, C324b, PO Box 63, Biomedicum Helsinki FIN-00014, Finland
}

(Received 29 October 2008 - Revised 13 March 2009 - Accepted 19 March 2009 - First published online 27 April 2009)

A diet rich in lignans has been suggested to be protective against a range of chronic diseases. The distribution and metabolic fate of lignans is, however, very poorly understood. We fed high-fibre wheat breads low in lignans $(n 8)$ or high-fibre rye breads $(n 9)$ rich in plant lignans to pigs for 58-67 d, and analysed the content of plant lignans and their metabolites in the diet, blood, bile, faeces, urine and selected tissues. Apparent faecal digestibility of dietary precursors was higher than of total (plant- and entero-) lignans due to conversion to enterolactone and enterodiol. The digestibility of lariciresinol and matairesinol was lower than that of the sum of plant lignans. This suggests that interconversion of plant lignans during digestion and enterohepatic circulation occur without complete conversion to enterolignans. The majority of lignans present in plasma and urine was in the form of enterolignans, but up to $23 \%$ in the plasma, and $11 \%$ in the urine of the rye-fed pigs were in the form of plant lignans. There was a very high concentration of lignans in bile from the rye-fed pigs with as much as $77 \%$ in the form of plant lignans. Lignans were detected in the tissue of colon, liver, breast and brain at a much higher level with rye than with wheat, but only in the form of enterolactone. The importance and implications of systemic exposure to plant lignans remain to be elucidated.

Lignans: Whole grains: Metabolism: Plasma: Tissue: Bile

Several epidemiological, intervention and animal studies point to a protective effect of a lignan-rich diet towards a range of lifestyle-related diseases such as certain cancers, CVD, and possible involvement in glycaemic control ${ }^{(1-3)}$. Intervention studies with lignan-rich food such as flaxseed ${ }^{(4)}$ and rye bread $^{(5)}$ reduce the cholesterol level in hypercholesterolaemic subjects. The high content of plant lignans in the diet may contribute to this hypocholesterolaemic effect. Increased enterolactone (ENL) concentrations in serum have been associated with a lower risk of $\mathrm{CVD}^{(6)}$, and a high lignan intake to lower aortic stiffness ${ }^{(7)}$ and TAG level ${ }^{(8)}$. Mechanisms suggested to be involved in the protective effect of some lignans against CVD include antioxidative effects ${ }^{(9)}$, stimulation of sex hormone-binding globulin synthesis ${ }^{(10)}$, up-regulation of LDL receptor activity ${ }^{(11)}$, inhibition of $7 \alpha$-hydroxylase and acyl-CoA-cholesterol acyltransferase activity $^{(12)}$ and increased nitrogen oxide production ${ }^{(13)}$.

Originally only secoisolariciresinol and matairesinol were identified as precursors of the enterolignans ENL and enterodiol (END). Improved methods of analysis led to the discovery of more precursors such as pinoresinol, syringaresinol, lariciresinol and medioresinol ${ }^{(14,15)}$, and recently further eighteen plant lignans were identified in food items including four found in rye and wheat ${ }^{(16)}$. These plant lignans account for $30-45 \%$ of the total content of lignans in rye and $1-18 \%$ of the total content in wheat ${ }^{(16)}$. The discovery of new enterolignan precursors and the recent development of methods to quantify them in food matrices, excreta and body fluids and tissues made possible the estimation of dietary lignan bioavailability and metabolism. We have recently reported that a diet based on wholegrain rye enriched with rye bran compared with wheat flour enriched with purified wheat fibre at iso-dietary fibre levels had a hypocholesterolaemic effect in hypercholesterolaemic pigs ${ }^{(17)}$. From the present study, it was concluded that the ability of dietary fibre from rye to interfere with digestion and absorption was more important for whole-body cholesterol homeostasis than regulation in the liver at gene level. Here we report new results on the quantitative metabolism and concentrations in biofluids and tissues of lignans in a pig model using high-fat cholesterol-enriched bread-based diets based on either wheat flour and refined wheat fibre, or wholegrain rye with added rye fibre.

Abbreviations: CEAD, coulometric electrode array detector; END, enterodiol; ENL, enterolactone; MeOH, methanol

* Corresponding author: Dr Helle Nygaard Lærke, fax +45 899913 78, email Hellen.laerke@agrsci.dk 


\section{Materials and methods}

\section{Diets}

The study included two experimental diets: a high-fibre rye bread-based diet and a high-fibre wheat bread-based diet. Before administration of the high-fibre diets the pigs were fed an atherogenic diet for 2 weeks, followed by a wash-out period consisting of a low-fat wheat flour-based diet for $2-3$ weeks as previously described ${ }^{(17)}$. The diets during the experimental period consisted of breads high in dietary fibre and enriched with fat and cholesterol (Table 1). The rye bread (produced at Holstebro Technical College, Denmark) contained finely ground wholegrain rye (Valsemøllen, Esbjerg, Denmark) and ground rye bran (Nordmills, Uppsala, Sweden), while the wheat bread (produced at Lantmännen Unibake, Karup, Denmark) contained white wheat flour supplemented with refined cellulose-rich wheat fibre (Vitacel WF 600; J. Rettenmaier \& Söhne GmbH, Rosenberg, Germany) in order to achieve the same dietary fibre level. Whey protein concentrate (Lacprodan 87; Arla Foods Amba, Viby, Denmark) was used to adjust the protein content, and

Table 1. Ingredients $\left(\mathrm{g} / 100 \mathrm{~g}\right.$ as-is) ${ }^{\star}$, DM content $(\mathrm{g} / 100 \mathrm{~g}$ as-is) and content of macronutrients and plant lignans (per $100 \mathrm{~g} \mathrm{DM}$ ) in the experimental breads

\begin{tabular}{|c|c|c|}
\hline & Wheat & Rye \\
\hline \multicolumn{3}{|l|}{ Ingredients ( $\mathrm{g} / 100 \mathrm{~g}$ as-is) } \\
\hline White wheat flour & $52 \cdot 8$ & 0.0 \\
\hline Wholemeal rye flour & 0.0 & $31 \cdot 0$ \\
\hline Vitacel WF $600 \dagger$ & $15 \cdot 7$ & 0.0 \\
\hline Rye bran & 0.0 & $40 \cdot 0$ \\
\hline Whey protein concentrate & 2.5 & 0.0 \\
\hline Yeast & $2 \cdot 0$ & $2 \cdot 0$ \\
\hline Sugar & 1.5 & 1.5 \\
\hline Egg powder & $15 \cdot 0$ & $15 \cdot 0$ \\
\hline Rapeseed oil & $2 \cdot 0$ & $2 \cdot 0$ \\
\hline Lard & $5 \cdot 0$ & $5 \cdot 0$ \\
\hline Cholesterol & 0.5 & 0.5 \\
\hline Vitamin-mineral mixture $\ddagger$ & $3 \cdot 0$ & $3 \cdot 0$ \\
\hline \multicolumn{3}{|l|}{ Composition } \\
\hline DM (g/100 g fresh weight) & $66 \cdot 1$ & $68 \cdot 0$ \\
\hline Energy (MJ) & $21 \cdot 10$ & $21 \cdot 16$ \\
\hline Ash (g) & 3.9 & $5 \cdot 0$ \\
\hline Protein (g) & $18 \cdot 2$ & $17 \cdot 2$ \\
\hline $\mathrm{HCl}$ fat $(\mathrm{g})$ & $15 \cdot 3$ & $15 \cdot 9$ \\
\hline Starch and sugar (g) & 43.7 & $38 \cdot 4$ \\
\hline Dietary fibre $\S(\mathrm{g})$ & $19 \cdot 4$ & $20 \cdot 3$ \\
\hline NSP $(g)$ & $17 \cdot 3$ & $16 \cdot 3$ \\
\hline Klason lignin (g) & $2 \cdot 2$ & 4.0 \\
\hline Plant lignans $(\mu \mathrm{g})$ & $124 \cdot 0$ & $4152 \cdot 7$ \\
\hline Secoisolariciresinol & $7 \cdot 0$ & 77.6 \\
\hline Matairesinol & - & $79 \cdot 3$ \\
\hline Lariciresinol & $19 \cdot 9$ & 508.4 \\
\hline Pinoresinol & 8.5 & $572 \cdot 8$ \\
\hline Syringaresinol & 77.9 & 2628.6 \\
\hline Medioresinol & $10 \cdot 6$ & $286 \cdot 0$ \\
\hline
\end{tabular}

\section{-, Not detectable.}

* Before water addition and baking.

†J. Rettenmaier \& Söhne GmbH (Rosenberg, Germany).

†Provided (mg/kg diet): $\mathrm{Ca}\left(\mathrm{H}_{2} \mathrm{PO}_{4}\right)_{2}, 6642 ; \mathrm{NaCl}, 4122 ; \mathrm{CaCO}_{3}, 16580 ; \mathrm{FeSO}_{4}$ $7 \mathrm{H}_{2} \mathrm{O}, 286 ; \mathrm{ZnO}, 114 ; \mathrm{Mn}_{3} \mathrm{O}_{4}, 41 ; \mathrm{CuSO}_{4} \cdot 5 \mathrm{H}_{2} \mathrm{O}, 92 ; \mathrm{KI}, 0.3 ; \mathrm{Na}_{2} \mathrm{SeO}_{3} \cdot 5 \mathrm{H}_{2} \mathrm{O}$ 0.8 ; retinoacetate, 2.1; cholecalciferol, 0.03 ; $\alpha$-tocopherol, 69 ; menadione, 2.52 ; riboflavin, 4.58; D-pantothenic acid, 12.59; cyanocobalamin (vitamin $B_{12}$ ), 0.025; thiamin (vitamin $B_{1}$ ), 2.52; niacin, 25.2; pyridoxine (vitamin $B_{6}$ ), 3.78; biotin, 0.063 $\S$ Dietary fibre was calculated as the sum of NSP and Klason lignin. lard, egg powder (Danæg Products A/S, Roskilde, Denmark) and cholesterol (Sigma-Aldrich Co., St Louis, MO, USA) to increase the fat and cholesterol content. The diets were stored at $-20^{\circ} \mathrm{C}$ until consumption, and chromic oxide $\left(\mathrm{Cr}_{2} \mathrm{O}_{3}\right)$ was added to ground experimental diets during the final 2.5 weeks of the study.

\section{Experimental design and animals}

A total of seventeen Duroc $\times$ Danish Landrace $\times$ Yorkshire gilts, aged 4 months and obtained from Aarhus University, Faculty of Agricultural Sciences (Foulum, Denmark), were used for the study. The seventeen pigs, responding to ad libitum feeding of the atherogenic diet for 2 weeks by having elevated plasma cholesterol levels (7.2 (SEM 0.51) $\mathrm{mmol} / \mathrm{l}$ ), were subsequently fed the low-fat wash-out diet for 2-3 weeks, by which the cholesterol level fell again to 2.5 (SEM 0.08$) \mathrm{mmol} / \mathrm{l}^{(17)}$. Following this, the pigs were fed the experimental diets for 6-7 weeks, followed by about 2.5 weeks where the breads were ground and $\mathrm{Cr}_{2} \mathrm{O}_{3}(2 \mathrm{~g} / \mathrm{kg}$ on an as-is basis) was added. In week 2 after chromium addition to the diets the pigs were transferred to metabolism cages for $7 \mathrm{~d}$, where faeces and urine were collected quantitatively on a daily basis and pooled per pig. Urine was collected over $4 \mathrm{~g}$ ascorbic acid per bottle, and $\mathrm{pH}$ of the collected urine was measured on a daily basis. The pigs were subsequently returned to their pens and euthanised 2-4d after the end of the balance period. When not placed in metabolism cages, the pigs were housed individually in $4 \mathrm{~m}^{2}$ smooth-walled pens with a concrete floor. The feed intake during the period, where the pigs ate the experimental bread-based diets, was restricted to $2 \mathrm{~kg} / \mathrm{d}$ increasing to $3 \mathrm{~kg} / \mathrm{d}$ for about the last 2.5 weeks of the study.

Postprandial blood samples from the jugular vein, lateral auricular artery, hepatic vein and portal vein were taken into heparinised vacutainers $3 \mathrm{~h}$ after the morning meal from anaesthetised pigs. The pigs were subsequently euthanised with an overdose of sodium pentobarbital followed by exsanguination $^{(17)}$. Samples were taken directly from the gall bladder and the urine bladder and stored frozen. Biopsies taken from the left lobe of the liver, tissue of the mid colon, breast and the brain were quick-frozen in liquid $\mathrm{N}_{2}$, and stored at $-80^{\circ} \mathrm{C}$ until analysis.

The animal experiment was conducted according to protocols approved by the Danish Animal Experiments Inspectorate and complied with the guidelines of the Danish Ministry and Justice concerning animal experimentation and care of animals under study.

\section{Analytical methods}

All analyses were performed in duplicate. Freeze-dried samples of diets and faeces were ground to a particle size of less than $0.5 \mathrm{~mm}$ before analysis. The DM content of feed and freeze-dried faeces was determined by drying to constant weight at $105^{\circ} \mathrm{C}$ for $20 \mathrm{~h} . \mathrm{Cr}_{2} \mathrm{O}_{3}$ concentrations in faeces and diets were analysed as described by Schürch et al. ${ }^{(18)}$. Macronutrient composition of the diets was analysed as previously described ${ }^{(17)}$.

A total of six plant lignans, namely secoisolariciresinol, matairesinol, lariciresinol, pinoresinol, medioresinol and 
syringaresinol, and two enterolignans, END and ENL, were profiled in the different samples. The content of plant lignans in the diets was analysed by isotope dilution GC-MS in the selected ion-monitoring mode (ID-GC-MS-SIM) as previously described $^{(19)}$. The same instrumental technique was used for the determination of plant lignans and enterolignans in faeces, using the corresponding extraction protocol ${ }^{(14)}$. The lignan profile in urine ${ }^{(20)}$, plasma and bile ${ }^{(21)}$ was analysed by HPLC coupled with a coulometric electrode array detector (HPLC-CEAD)

The procedure for determination of lignans in tissues was as follows. Freeze-dried liver and brain tissue samples were ground to a fine powder, whereas colon and breast tissues were homogenised by crushing frozen with an Ultra Turrax T8 (IKA Werke GmbH \& Co. KG, Staufen, Germany). To $50 \mathrm{mg}$ of the samples and controls $300 \mu \mathrm{l}$ distilled water were added and the samples were sonicated for $10 \mathrm{~min}$. ${ }^{3}$ H-labelled oestradiol-17 $\beta$-glucuronide (18000 counts per min, NEN ${ }^{\circledR}$; Perkin-Elmer, Shelton, CT, USA) in methanol $(\mathrm{MeOH})$-water $(9: 1, \mathrm{v} / \mathrm{v})$ was added to serve as an internal standard for recovery correction. Thereafter $700 \mu \mathrm{l} \mathrm{MeOH}$ were added and the sample kept overnight at $-20^{\circ} \mathrm{C}$ in order to precipitate proteins and lipophilic material. The samples were centrifuged $(3000 \mathrm{rpm})$ for $10 \mathrm{~min}$ below $0^{\circ} \mathrm{C}$, and the supernatant fraction collected. The precipitate was washed once with $1 \mathrm{ml}$ ice-cold $\left(-20^{\circ} \mathrm{C}\right) 70 \% \mathrm{MeOH}$, centrifuged. The two supernatant fractions were combined, and evaporated under $\mathrm{N}_{2}$ at $50^{\circ} \mathrm{C}$ until only water remained $(500 \mu \mathrm{l})$, and subsequently still extracted twice with $2.5 \mathrm{ml}$ $\mathrm{n}$-hexane by vortex mixing for $4 \mathrm{~min}$. The water phase was frozen in a dry-ice ethanol bath, and the n-hexane was discarded. The remaining traces of $n$-hexane were evaporated from the sample, and the water phase $(500 \mu \mathrm{l})$ was hydrolysed by adding $500 \mu \mathrm{l}$ of hydrolysis reagent containing $\beta$-glucuronidase $(0 \cdot 2 \mathrm{U} / \mathrm{ml})$, sulfatase $(2 \mathrm{U} / \mathrm{ml})$ and $0 \cdot 1 \mathrm{M}$-acetate buffer (pH 5.0) and incubated overnight at $37^{\circ} \mathrm{C}$. The samples were extracted twice with $3 \mathrm{ml}$ diethyl ether, mixing for $4 \mathrm{~min}$, then evaporated to dryness and reconstituted in $500 \mu \mathrm{l}$ $\mathrm{MeOH}$. A $3 \mathrm{~cm}$ column of ion exchanger QAE-Ac in $\mathrm{MeOH}$ was prepared in a disposable Pasteur pipette and the sample in $\mathrm{MeOH}$ was applied to the column. The sample vial was rinsed once with $300 \mu \mathrm{l} \mathrm{MeOH}$ and applied to the column. The lignans were further eluted with $4 \mathrm{ml} \mathrm{MeOH}$, and evaporated to dryness. For the HPLC analysis, the dry sample was reconstituted with $100 \mu \mathrm{l} \mathrm{MeOH}, 100 \mu \mathrm{l}$ HPLC mobile phase (20\% phase B/A; see below) was added, and $10 \mu \mathrm{l}$ immediately subjected to HPLC-CEAD. A subsample of $20 \mu \mathrm{l}$ was taken for determination of $\left[{ }^{3} \mathrm{H}\right]$ oestradiol-17 $\beta$ glucuronide recovery to correct for losses during the procedure. The mean recovery of $\left[{ }^{3} \mathrm{H}\right]$ oestradiol-17 $\beta$-glucuronide for liver and colon tissues was $62.4 \%(\mathrm{CV} \%$ 14.7) and for brain and breast tissues $84.2 \%$ (CV\% 10.4).

We used an HPLC system (ESA Biosciences, Inc., Chelmsford, MA, USA) equipped with a model 540 autosampler, two model 580 solvent pumps, and a model 5600 CEAD with eight electrode pairs. The analytical column was an Inertsil ODS-3 (GL Sciences Inc., Tokyo, Japan), $3 \times 150 \mathrm{~mm}$ with particle size $3 \mu \mathrm{m}$, connected to a Quick Release RP-18 (Upchurch Scientific Inc., WA, USA) $3 \times 10 \mathrm{~mm}$ guard column. The mobile phases used in HPLC-CEAD were: (A) $50 \mathrm{~mm}$-sodium acetate buffer-MeOH (80:20, v/v); (B) $50 \mathrm{~mm}$-sodium acetate buffer ( $\mathrm{pH}$ 5.0)-MeOH-acetonitrile (40:40:20, by vol.). The chromatographic conditions were: detection potential, $660 \mathrm{mV}$; flow rate, $0.3 \mathrm{ml} / \mathrm{min}$. The separation of compounds was carried out using gradient elution. All standards were dissolved in $\mathrm{MeOH}-20 \% \mathrm{~B} / \mathrm{A}(1: 1, \mathrm{v} / \mathrm{v})$. The seven-point standard curve ranged from 3.5 to $1393 \mathrm{ng} / \mathrm{ml}$ for ENL. No other lignans were detected in the tissue samples.

All lignan analyses included hydrolysis of any conjugate (glucosides in the diets, glucuronides and sulfates in the plasma and bile) and therefore the results are expressed as aglycones.

\section{Calculations and statistical analysis}

The apparent digestibility of the individual lignans $(X)$ was calculated relative to the concentration of $\mathrm{Cr}_{2} \mathrm{O}_{3}$ as:

$$
\text { Digestibility of } X=1-\frac{\mathrm{Cr}_{2} \mathrm{O}_{3(d)} \times X_{(f)}}{\mathrm{Cr}_{2} \mathrm{O}_{3(f)} \times X_{(d)}},
$$

where $X_{(d)}$ and $X_{(f)}$ denote the concentrations of the lignans $(X)$ in diet and faeces, respectively, and $\mathrm{Cr}_{2} \mathrm{O}_{3(d)}$ and $\mathrm{Cr}_{2} \mathrm{O}_{3(f)}$ are the corresponding concentrations of $\mathrm{Cr}_{2} \mathrm{O}_{3}$.

The estimated production of enterolignans ( $\left.\mathrm{EL}_{\text {prod }}\right)$ was calculated as:

$$
\mathrm{EL}_{\text {prod }}=\mathrm{PL}_{\text {intake }}-\left(\mathrm{PL}_{\text {faeces }}+\mathrm{PL}_{\text {urine }}\right),
$$

where $\mathrm{PL}_{\text {intake }}, \mathrm{PL}_{\text {faeces }}$ and $\mathrm{PL}_{\text {urine }}$ are the quantitative intake and excretion of plant lignans in faeces and urine.

The excretion of enterolignans ( $\mathrm{EL}_{\text {excretion }}$ ) was calculated as:

$$
\mathrm{EL}_{\text {excretion }}=\mathrm{EL}_{\text {urine }}+\mathrm{EL}_{\text {faeces }} \text {, }
$$

where $\mathrm{EL}_{\text {urine }}$ and $\mathrm{EL}_{\text {faeces }}$ are the sum of excreted ENL and END in faeces and urine during the $7 \mathrm{~d}$ collection period.

All statistical analyses were carried out using SAS for Windows (version 8.2; SAS Institute Inc., Cary, NC, USA). The level of significance was $P<0.05$ in all analyses. Variables meeting the criteria of normal distribution are reported as least squares means (LSMeans) with their standard errors (SEM). When variables were not normally distributed, statistical evaluation was performed on logarithmic transformations of the values, and results are reported as geometric means with $95 \%$ CI.

The effect of diet and site of blood collection on plasma concentrations of lignans was examined by PROC MIXED, taking repeated measurements made on the same individuals into account ${ }^{(22)}$.

The effect of diet on faecal and urine concentrations, digestibility, and excretion in urine and faeces were subjected to one-way analysis using PROC MIXED with GROUP option to account for variance heterogeneity.

\section{Results}

The markedly higher content of plant lignans in the rye diet compared with the wheat diet enriched with purified wheat dietary fibre (Table 1) resulted in a thirty-four times higher intake of lignans (Table 2). Syringaresinol was by far the dominating component of the rye diet, accounting for $60 \%$ of the total plant lignan content, while secoisolariciresinol 
Table 2. Intake, faecal excretion and digestibility of lignans from pigs fed the experimental wheat or rye diets (Least squares means (LSMeans) with their standard errors)

\begin{tabular}{|c|c|c|c|c|c|c|c|c|c|c|}
\hline & \multirow{2}{*}{\multicolumn{2}{|c|}{ Intake $(\mu \mathrm{mol} / \mathrm{d})$}} & \multicolumn{4}{|c|}{ Excretion $(\mu \mathrm{mol} / \mathrm{d})$} & \multicolumn{4}{|c|}{ Digestibility† } \\
\hline & & & \multicolumn{2}{|c|}{ Wheat } & \multicolumn{2}{|c|}{ Rye } & \multicolumn{2}{|c|}{ Wheat } & \multicolumn{2}{|c|}{ Rye } \\
\hline & Wheat & Rye & LSMean & SEM & LSMean & SEM & LSMean & SEM & LSMean & SEM \\
\hline Total lignans & $6 \cdot 2$ & $213 \cdot 6$ & $1 \cdot 7$ & 0.067 & $74 \cdot 13^{\star \star \star}$ & 1.901 & 0.70 & 0.013 & $0.61^{\star \star \star}$ & 0.007 \\
\hline Enterolignans & - & - & 0.58 & 0.039 & $42 \cdot 34^{\star \star \star}$ & $1 \cdot 210$ & & & & \\
\hline Enterolactone & - & - & 0.56 & 0.038 & $41 \cdot 93^{\star \star *}$ & $1 \cdot 179$ & & & & \\
\hline Enterodiol & - & - & 0.02 & 0.002 & $0.41^{\star \star \star}$ & 0.042 & & & & \\
\hline Plant lignans & $6 \cdot 2$ & $213 \cdot 6$ & $1 \cdot 12$ & 0.058 & $31 \cdot 8^{\star \star \star}$ & 0.979 & 0.80 & 0.013 & 0.83 & 0.004 \\
\hline Secoisolariciresinol & 0.4 & 4.4 & 0 & 0.002 & $0.49^{\star \star \star}$ & 0.048 & 0.99 & 0.005 & $0.87^{\star \star \star}$ & 0.013 \\
\hline Matairesinol & - & 4.5 & 0.02 & 0.002 & $1 \cdot 41^{\star * \star}$ & 0.070 & - & - & 0.65 & 0.016 \\
\hline Lariciresinol‡ & $1 \cdot 1$ & $28 \cdot 8$ & 0.32 & 0.014 & $7 \cdot 12^{\star \star \star}$ & 0.330 & 0.69 & 0.016 & 0.72 & 0.011 \\
\hline Pinoresinol & 0.5 & $32 \cdot 6$ & 0 & 0.003 & $1 \cdot 27^{\star \star \star}$ & 0.089 & 0.99 & 0.008 & $0.96^{\star *}$ & 0.003 \\
\hline Syringaresinol & 3.7 & $128 \cdot 3$ & 0.74 & 0.054 & $20 \cdot 31^{\star \star *}$ & 0.723 & 0.78 & 0.019 & 0.82 & 0.005 \\
\hline Medioresinol & 0.5 & 15 & 0.04 & 0.004 & $1 \cdot 2^{* * *}$ & 0.050 & 0.93 & 0.008 & 0.91 & 0.005 \\
\hline
\end{tabular}

- , Not detectable.

LSMean was significantly different from that for wheat: * $P<0.05,{ }^{* \star} P<0.01,{ }^{* \star *} P<0.001$.

$\dagger$ For digestibility calculation, see Calculations and statistical analysis section.

$\ddagger$ Including isolariciresinol in faeces.

and matairesinol accounted for only $4-6 \%$ of the total dietary intake of lignans.

The higher intake of plant lignans with the rye diet was reflected in a twenty-eight times higher total faecal excretion of plant lignans and enterolignans compared with the wheat diet (Table 2). Enterolignans accounted for $34-57 \%$ of the total faecal excretion of lignans, while $43-66 \%$ was in the form of plant lignans.

The apparent faecal digestibility of the plant lignans was, in decreasing order: pinoresinol $>$ medioresinol $>$ secoisolariciresinol $>$ syringaresinol $>$ lariciresinol $>$ matairesinol (Table 2).

As could be expected from the higher intake, there was a much higher concentration of enterolignans in plasma at all sites (portal vein, hepatic vein, lateral auricular artery and jugular vein) of pigs fed the rye compared with the wheat diet (Table 3). ENL was the primary circulating lignan accounting for $58-85 \%$ of the total lignan content in plasma obtained from all four sites of collection. END, on the other hand, accounted for only approximately $1 \%$ of the circulating lignans. Overall, the concentration of lignans was highest in the portal and hepatic vein, while the concentration was significantly reduced in peripheral venous and arterial blood.

The bile of the wheat-fed pigs contained no measurable lignans, whereas the bile from the rye-fed pigs contained 6.2 (SEM 0.9) $\mu \mathrm{mol} / \mathrm{l}$. Plant lignans accounted for $77 \%$ of the measured lignans, and was dominated by matairesinol followed by lariciresinol, and secoisolariciresinol (Fig. 1). Enterolignans in the form of ENL accounted, on the other hand, only for $23 \%$ of the total lignan content in bile from the rye-fed pigs.

Both concentrations of lignans in bladder urine and in urine collected over a $7 \mathrm{~d}$ collection period were higher in pigs fed the rye compared with the wheat-fed pigs (Table 4). The lower concentration in urine from the $7 \mathrm{~d}$ collection compared with bladder urine may in part be explained by dilution with drinking water spillage collected from the cages together with urine. However, for calculation of quantitative excretion, this lower concentration is counteracted by the collection of larger volumes. Based on the $7 \mathrm{~d}$ quantitative collection of urine, and the concentration of lignans herein, the total urinary excretion of plant lignans and enterolignans was calculated to be 1.4 (SEM 0.02) $\mu \mathrm{mol} / \mathrm{d}$ for pigs fed the wheat diet, whereas the urinary excretion was 71.0 (SEM 5.79) $\mu \mathrm{mol} / \mathrm{d}$ for pigs on the rye diet $(P<0.0001)$. While plant lignans could not be detected in urine of the wheat-fed pigs, they contributed with 7.6 (SEM 0.72$) \mu \mathrm{mol} / \mathrm{d}$ for pigs on the rye diet.

Significant concentrations of enterolignans in the form of ENL were found in the colon, liver and breast tissue, and minor concentrations in the brain of the rye-fed pigs (Table 5). ENL was also found in lower concentrations in the colon, liver and breast tissue of the wheat-fed pigs, while no measurable lignan was found in brain tissue. Thus, the highest concentrations are found in tissues that are in close proximity to the production site, the gut, and the organ for reconjugation, the liver.

The estimated production of enterolignans calculated from the intake and excretion of plant lignans was 174 (SEM 1.4) $\mu \mathrm{mol} / \mathrm{d}$ for the rye compared with 5 (SEM 0.1 ) $\mu \mathrm{mol} / \mathrm{d}$ for the wheat diet (Fig. 2). Thus, the estimated production of enterolignans was $1.5-2.5$ times higher than the 2 (SEM $0 \cdot 2$ ) and 106 (SEM 4.9) $\mu \mathrm{mol} / \mathrm{d}$ actually recovered in faeces and urine from the wheat- and the rye-fed pigs, respectively.

\section{Discussion}

The diets were formulated to be similar in macronutrients but different in dietary fibre characteristics and content of plant lignans ${ }^{(17)}$. As the plant lignans are concentrated in the aleurone and pericarp/testa layer of the rye kernel $^{(23,24)}$ the experimental rye bread enriched with rye bran had a lignan content that was about seven times higher than in ordinary rye bread $(594 \mu \mathrm{g} / 100 \mathrm{~g} \mathrm{DM})^{(25)}$. Lignan analysis of the diets confirmed other studies showing that secoisolariciresinol and matairesinol contribute only marginally to the total intake of plant lignans ${ }^{(19,25,26)}$. 
Table 3. Concentration (nmol/l) of lignans in plasma collected $3 \mathrm{~h}$ postprandially from the portal vein, hepatic vein, a peripheral artery (lateral auricular artery) and jugular vein of pigs fed fibre-enriched wheat or rye diets*

(Geometric means and $95 \%$ confidence intervals or least squares means (LSMeans) with their standard errors)

\begin{tabular}{|c|c|c|c|c|c|c|c|c|c|c|c|c|c|c|}
\hline & & & $\begin{array}{l}\text { Total } \\
\text { lignans }\end{array}$ & Enterolignans & ENL & END & $\begin{array}{l}\text { Plant } \\
\text { lignans }\end{array}$ & SECO & MAT & IsoLar & LAR & PIN & SYR & MED \\
\hline \multirow[t]{5}{*}{ Portal vein } & Wheat & $\begin{array}{l}\text { Geometric mean } \\
95 \% \mathrm{Cl}\end{array}$ & $\begin{array}{l}5 \cdot 7 \\
4 \cdot 4,7.5\end{array}$ & $\begin{array}{l}5 \cdot 7 \\
4 \cdot 2,7 \cdot 7\end{array}$ & $\begin{array}{l}3 \cdot 9 \\
2 \cdot 9,5 \cdot 3\end{array}$ & & & & & & & & & \\
\hline & & $\begin{array}{l}\text { LSMean } \\
\text { SEM }\end{array}$ & & & & $\begin{array}{l}1.8 \\
0.5\end{array}$ & - & - & - & - & - & - & - & - \\
\hline & Rye & $\begin{array}{l}\text { Geometric mean } \\
95 \% \mathrm{Cl}\end{array}$ & $\begin{array}{l}193.5 \\
150 \cdot 1,249 \cdot 4\end{array}$ & $\begin{array}{l}149 \cdot 0 \\
112 \cdot 6,197 \cdot 1\end{array}$ & $\begin{array}{l}147 \cdot 3 \\
110 \cdot 3,196 \cdot 9\end{array}$ & & & & & & & & & \\
\hline & & LSMean & & & & $2 \cdot 0$ & $44 \cdot 1$ & 3.9 & $6 \cdot 7$ & $1 \cdot 7$ & $13 \cdot 1$ & $7 \cdot 7$ & $9 \cdot 7$ & $1 \cdot 3$ \\
\hline & & SEM & & & & 0.5 & 6.5 & $1 \cdot 1$ & 1.9 & 0.3 & 1.5 & 1.4 & $1 \cdot 2$ & 0.2 \\
\hline \multirow[t]{5}{*}{ Hepatic vein } & Wheat & $\begin{array}{l}\text { Geometric mean } \\
95 \% \mathrm{Cl}\end{array}$ & $\begin{array}{l}5 \cdot 0 \\
4 \cdot 2,6 \cdot 0\end{array}$ & $\begin{array}{l}5 \cdot 0 \\
4 \cdot 1,6 \cdot 1\end{array}$ & $\begin{array}{l}3 \cdot 8 \\
3 \cdot 1,4 \cdot 7\end{array}$ & & & & & & & & & \\
\hline & & $\begin{array}{l}\text { LSMean } \\
\text { SEM }\end{array}$ & & & & $\begin{array}{l}1 \cdot 2 \\
0 \cdot 3\end{array}$ & - & - & - & - & - & - & - & - \\
\hline & Rye & $\begin{array}{l}\text { Geometric mean } \\
95 \% \mathrm{Cl}\end{array}$ & $\begin{array}{l}178 \cdot 4 \\
149 \cdot 8,212 \cdot 5\end{array}$ & $\begin{array}{l}147 \cdot 0 \\
120 \cdot 5,179 \cdot 2\end{array}$ & $\begin{array}{l}145 \cdot 8 \\
118 \cdot 1,180 \cdot 0\end{array}$ & & & & & & & & & \\
\hline & & LSMean & & & & 1.4 & $31 \cdot 2$ & 3.4 & 3.6 & 1.9 & $11 \cdot 2$ & 4.9 & $3 \cdot 8$ & 0.8 \\
\hline & & SEM & & & & 0.3 & $2 \cdot 1$ & 0.7 & 0.9 & $1 \cdot 0$ & $1 \cdot 0$ & $0 \cdot 7$ & 0.5 & $0 \cdot 1$ \\
\hline \multirow{6}{*}{$\begin{array}{l}\text { Lateral } \\
\quad \text { auricular artery }\end{array}$} & Wheat & Geometric mean & $6 \cdot 0$ & $6 \cdot 0$ & $3 \cdot 6$ & & & & & & & & & \\
\hline & & $95 \% \mathrm{Cl}$ & $4 \cdot 4,8 \cdot 2$ & $4 \cdot 4,8 \cdot 2$ & $2 \cdot 5,5 \cdot 2$ & & & & & & & & & \\
\hline & & $\begin{array}{l}\text { LSMean } \\
\text { SEM }\end{array}$ & & & & $\begin{array}{l}2 \cdot 2 \\
0.3\end{array}$ & - & - & - & - & - & - & - & - \\
\hline & Rye & $\begin{array}{l}\text { Geometric mean } \\
95 \% \mathrm{Cl}\end{array}$ & $\begin{array}{l}110 \cdot 8 \\
82 \cdot 8,148 \cdot 3\end{array}$ & $\begin{array}{l}95 \cdot 0 \\
70 \cdot 5,128 \cdot 1\end{array}$ & $\begin{array}{l}94 \cdot 1 \\
66 \cdot 1,133 \cdot 9\end{array}$ & & & & & & & & & \\
\hline & & LSMean & & & & $1 \cdot 1$ & $16 \cdot 5$ & 1.9 & $1 \cdot 4$ & 0.8 & $7 \cdot 2$ & $2 \cdot 1$ & $2 \cdot 2$ & 0.8 \\
\hline & & SEM & & & & 0.3 & 2.5 & 0.5 & 0.3 & 0.2 & 1.0 & 0.5 & 0.6 & 0.3 \\
\hline \multirow[t]{5}{*}{ Jugular vein } & Wheat & $\begin{array}{l}\text { Geometric mean } \\
95 \% \mathrm{Cl}\end{array}$ & $\begin{array}{l}4.0 \\
2.3,6.7\end{array}$ & $\begin{array}{l}4.0 \\
2.3,6.9\end{array}$ & $\begin{array}{l}2.3 \\
1.4 .3 .7\end{array}$ & & & & & & & & & \\
\hline & & $\begin{array}{l}\text { LSMean } \\
\text { SEM }\end{array}$ & & & & $\begin{array}{l}2 \cdot 2 \\
0.5\end{array}$ & - & - & - & - & - & - & - & - \\
\hline & Rye & $\begin{array}{l}\text { Geometric mean } \\
95 \% \mathrm{Cl}\end{array}$ & $\begin{array}{l}82 \cdot 7 \\
50 \cdot 2,136 \cdot 5\end{array}$ & $\begin{array}{l}69 \cdot 0 \\
41 \cdot 0,116 \cdot 1\end{array}$ & $\begin{array}{l}68 \cdot 3 \\
43 \cdot 6,107 \cdot 1\end{array}$ & & & & & & & & & \\
\hline & & LSMean & & & & 0.9 & $14 \cdot 7$ & 1.6 & 1.3 & 0.4 & $6 \cdot 3$ & $2 \cdot 1$ & $2 \cdot 6$ & 0.4 \\
\hline & & SEM & & & & 0.5 & $2 \cdot 0$ & 0.4 & 0.2 & 0.2 & 0.9 & 0.3 & 0.4 & 0.1 \\
\hline \multirow[t]{3}{*}{$P$} & Diet & & $<0.0001$ & $<0.0001$ & $<0.0001$ & NS & & & & & & & & \\
\hline & Site & & 0.0015 & 0.0041 & $<0.0001$ & 0.0018 & 0.0002 & 0.0053 & $<0.0001$ & $<0.0001$ & 0.0015 & 0.017 & 0.0004 & 0.0051 \\
\hline & Diet $\times$ site & & 0.0015 & 0.0024 & 0.19 & 0.0007 & & & & & & & & \\
\hline
\end{tabular}

ENL, enterolactone; END, enterodiol; SECO, secoisolariciresinol; MAT, matairesinol; IsoLar, isolariciresinol; LAR, lariciresinol; PIN, pinoresinol; SYR, syringaresinol; MED, medioresinol; -, below detection limit.

${ }^{*}$ For portal vein, lateral auricular artery and jugular vein: $n 8$ for wheat and $n 9$ for rye. For hepatic vein: $n 8$ for wheat and $n 7$ for rye. 


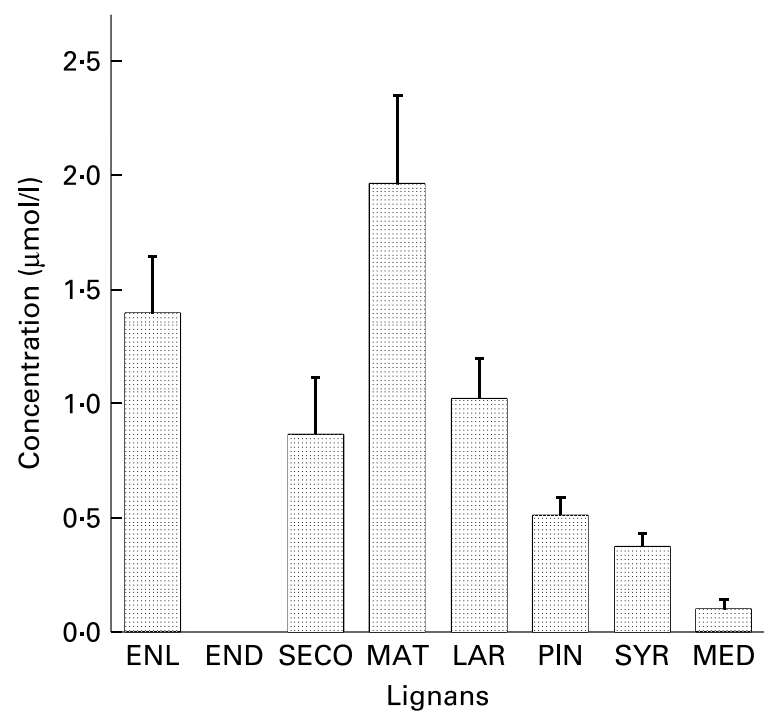

Fig. 1. Concentration of lignans $(\mu \mathrm{mol} / \mathrm{l})$ in bile taken from the gall bladder $3 \mathrm{~h}$ postprandial of pigs fed fibre-enriched rye diets. Values are least squares means, with standard errors represented by vertical bars. ENL, enterolactone; END, enterodiol; SECO, secoisolariciresinol; MAT, matairesinol; LAR, lariciresinol; PIN, pinoresinol; SYR, syringaresinol; MED, medioresinol.

The proportion of the ingested plant lignans that were excreted in faeces in the form of enterolignans was lower in the present study than in a similar study with pigs fed wheat and rye diets $(50-76 \%)^{(27)}$. The main reason is that fewer lignans were identified previously, and only matairesinol and secoisolariciresinol were analysed in faecal material ${ }^{(27)}$. In the faeces of human subjects on a habitual diet, 34-35\% lignans were excreted as enterolignans ${ }^{(14,28,29)}$. It has previously been shown that the amount of excreted lignans was higher in pigs than in human subjects, while the excretion per $g$ ingested dietary fibre was identical ${ }^{(24)}$.

The apparent digestibility of the individual plant lignans was generally higher than of the sum of plant lignans and enterolignans, reflecting that some lignans were converted to enterolignans before faecal excretion. The difference in digestibility among the plant lignans may partly be caused by conversion into intermediate plant lignans as previously shown in vitro ${ }^{(14)}$, and subsequent excretion without further conversion to enterolignans. The higher digestibility of lariciresinol, pinoresinol and syringaresinol in the present study than the estimated $10-19 \%$ in a previous study ${ }^{(27)}$ is most probably a consequence of differences in the method of determination (direct or indirect), and a higher microbial activity due to a longer period of adaptation to the diet in the present study. Metabolites of fermentation of syringaresinol have been detected in vitro but not identified ${ }^{(14)}$. To what extent these metabolites, directly or indirectly, contribute to the faecal excretion of plant lignans in modified form is presently not known. However, based on the in vitro conversion their contribution to the excretion of enterolignans is considered to be low.

The increased levels of enterolignans at all sites of blood collection confirm several intervention studies ${ }^{(30-33)}$, crosssectional $^{(34-36)}$ and animal studies ${ }^{(27)}$, where positive associations between intake of rye and wholegrain product and the ENL concentration in plasma or serum have been found. The higher concentrations of plant lignans and enterolignans in the portal vein than in the hepatic vein confirm previous findings that a substantial part of the lignans participate in the enterohepatic circulation or are converted to other metabolites. The significantly higher concentration of lignans in portal than in arterial blood is considered a consequence of the enrichment of the portal blood due to absorption from the gut $^{(27)}$. Generally, enterolignans are considered to be absorbed more efficiently than plant lignans ${ }^{(37)}$. Nevertheless, in the present study plant lignans accounted for $15-23 \%$ of the total lignan concentration in plasma. Some enterolignans may be reconverted to plant lignans in the liver before excretion to the intestine by the biliary route ${ }^{(24)}$ as indicated by the remethylation of the lignans arctiin and tracheloside in the liver of rats ${ }^{(38)}$. In vitro it has also been shown that ENL and END can undergo oxidative biotransformation by hepatic microsomes from rats and humans, which has been confirmed by the in vivo finding of several hydroxylated and methylated metabolites of ENL and END in the urine and bile of flaxseed-fed rats ${ }^{(39)}$.

Table 4. Concentration $(\mathrm{nmol} / \mathrm{l})$ of lignans in urine collected during a $7 \mathrm{~d}$ balance period or taken directly from the bladder at slaughter of pigs fed fibre-enriched wheat or rye diets

(Least squares means (LSMeans) with their standard errors)

\begin{tabular}{|c|c|c|c|c|c|c|c|c|}
\hline & \multicolumn{4}{|c|}{$7 \mathrm{~d}$ balance } & \multicolumn{4}{|c|}{ Bladder } \\
\hline & \multicolumn{2}{|c|}{ Wheat } & \multicolumn{2}{|c|}{ Rye } & \multicolumn{2}{|c|}{ Wheat } & \multicolumn{2}{|c|}{ Rye } \\
\hline & LSMean & SEM & LSMean & SEM & LSMean & SEM & LSMean & SEM \\
\hline Total lignans & 375 & 61 & $18552^{\star \star \star}$ & 1628 & 2013 & 468 & $36252^{\star \star \star}$ & 7795 \\
\hline Enterolignans & 375 & 61 & $16567^{\star \star \star}$ & 1478 & 1447 & 342 & $32884^{\star \star \star}$ & 7216 \\
\hline Enterolactone & 375 & 61 & $16269^{\star \star \star}$ & 1461 & 1412 & 335 & $32514^{\star *}$ & 7118 \\
\hline Enterodiol & - & & 297 & 35 & 35 & 11 & $370^{*}$ & 110 \\
\hline Plant lignans & - & & 1986 & 192 & 566 & 134 & $3368^{\star \star \star}$ & 666 \\
\hline Secoisolariciresinol & - & & 504 & 41 & 59 & 20 & $352^{*}$ & 95 \\
\hline Matairesinol & - & & 241 & 30 & 24 & 6 & $361^{* *}$ & 78 \\
\hline Isolariciresinol & - & & 132 & 20 & 84 & 21 & $224^{*}$ & 51 \\
\hline Lariciresinol & - & & 655 & 65 & 124 & 29 & $860^{* *}$ & 189 \\
\hline Pinoresinol & - & & 95 & 19 & 168 & 25 & $624^{\star *}$ & 120 \\
\hline Syringaresinol & - & & 309 & 41 & 87 & 38 & $791^{\star \star}$ & 203 \\
\hline Medioresinol & - & & 49 & 10 & 19 & 9 & $157^{\star \star}$ & 38 \\
\hline
\end{tabular}

LSMean was significantly different from that for wheat: * $P<0.05,{ }^{\star \star} P<0.01,{ }^{\star \star \star} P<0.001$. 
Table 5. Concentration of enterolactone (pmol/g fresh weight) in various tissues of pigs fed fibre-enriched wheat or rye diets

(Least squares means (LSMeans) with their standard errors)

\begin{tabular}{lccccc}
\hline & \multicolumn{2}{c}{ Wheat } & & \multicolumn{2}{c}{ Rye } \\
\cline { 2 - 3 } \cline { 6 - 7 } & LSMean & SEM & & LSMean & SEM \\
\hline Colon & $16 \cdot 7$ & 1.79 & & $691 \cdot 7^{\star \star *}$ & $93 \cdot 63$ \\
Liver & $2 \cdot 6$ & 0.50 & & $125 \cdot 0^{\star \star \star}$ & $19 \cdot 63$ \\
Breast & 0.3 & 0.21 & & $25 \cdot 8^{\star \star \star}$ & $4 \cdot 12$ \\
Brain & - & - & & $2 \cdot 3$ & 0.41 \\
\hline
\end{tabular}

-, Below detection limit.

${ }^{\star * \star}$ LSMean was significantly different from that for wheat $(P<0.001)$.

In the present study, the very high proportion of plant lignans found in bile and a higher proportion in portal blood compared with the other blood vessels suggest that plant lignans are diverted toward systemic elimination via the bile. It has previously been shown that simple monobenzene derivatives with molecular weight below $300 \mathrm{kDa}$ were poorly excreted in the bile, while compounds containing two or more rings and a highly polar anionic group with a minimum molecular weight of $325 \mathrm{kDa}$ were effectively excreted $^{(40)}$. The authors suggested that foreign compounds resembling the endogenous compounds (bile acids) would be effectively excreted in the bile.

Whether the excretion of the plant lignans by the biliary route is a protective mechanism only occurring after a systemic overload at very high intakes of plant lignans is not known. Because the plant lignan values are higher than the ENL values it seems that most of the ENL formed may pass the liver like oestriol-3-glucuronide for immediate excretion in urine $^{(41)}$, while the plant lignans may be selectively taken up by the liver cells, conjugated and excreted in the bile.

Before conjugation the plant lignans are certainly biologically active in the liver cells or in any other cell in the body. However, in conjugated form as in the bile, the lignans will not be biologically active again before they reach the intestine, are deconjugated by the microflora, and continue in a second enterohepatic circulation.

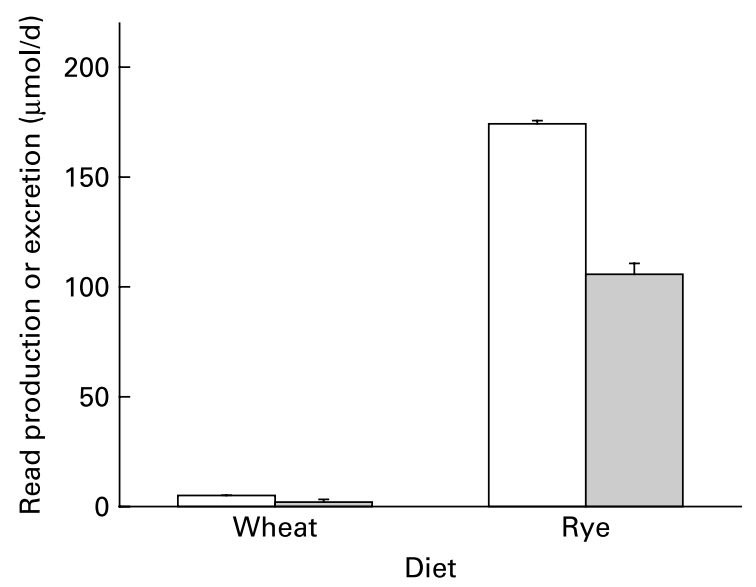

Fig. 2. Estimated production ( $\square$ ) and calculated excretion ( $\square$ ) of enterolignans $(\mu \mathrm{mol} / \mathrm{d})$ of pigs fed fibre-enriched wheat or rye diets. Values are least squares means, with standard errors represented by vertical bars.
To what extent the plant lignans have any potential protective effect against diseases such as cancer and CVD if not converted to enterolignans is not yet fully elucidated. The conversions to END and ENL are not necessary steps for biological action, but the relative importance of plant lignans respective to enterolignans is currently not known. We know very little about the biological effects of plant lignans, but high intake of matairesinol has been related to lower breast cancer risk ${ }^{(1,42)}$. Different in vitro assays suggest that both plant lignans and enterolignans have antioxidative capacity $^{(9,43-45)}$ with the antioxidative activities of secoisolariciresinol and matairesinol being significantly higher than that of ENL and END using a ferric-reducing/antioxidant power assay (FRAP) ${ }^{(43)}$. The additional aromatic methoxy group in the plant lignans was suggested to be responsible for the higher antioxidant activities ${ }^{(43)}$. However, the antioxidative effect has not been confirmed in human intervention studies $^{(45-48)}$

Ingestion of foods rich in plant lignans leads to higher urinary ENL concentrations ${ }^{(49,50)}$. The present results confirm previous results obtained after rye and wheat consumption both with pigs ${ }^{(27)}$ and human subjects ${ }^{(30)}$. Enterolignans were the dominating components of the lignans in urine, but plant lignans accounted for $11 \%$ of the lignans found in urine excreted from the rye-fed pigs. This suggests that approximately one-tenth of the lignans taken up from the intestine escapes microbial conversion and are absorbed directly as plant lignans, as also suggested in studies with rats $^{(37,51)}$. A large variation in the pattern of plant lignans and enterolignans has been observed in the urine of human subjects $^{(20)}$, where the excretion of plant lignans was higher than for those of enterolignans in two of ten subjects. Ingestion of secoisolariciresinol led to an increased excretion of lariciresinol in the urine of rats ${ }^{(51)}$, where lariciresinol was the main component of the excreted plant lignan also seen in the present study. This demonstrates that plant lignans can be converted to other plant lignans in vivo. The high excretion of lariciresinol may at least in part be caused by the high intake of pinoresinol as suggested by in vitro microbial conversion results obtained in a previous study ${ }^{(14)}$.

In the present study there was a slightly lower conversion from plant lignans to enterolignans than in the study of Bach Knudsen et al. ${ }^{(27)}$ that used comparable diets. In that study, the conversion was estimated to be 48 and $60 \%$ for pigs on the wheat- and rye-based diets, respectively, and the enterolignans were primarily excreted via the faeces $(46 \%$ of ingested plant lignans). In the present study only 9 and $20 \%$ of ingested plant lignans from the wheat and rye breads, respectively, were recovered as enterolignans in the faeces, while 27 and $35 \%$ of ingested plant lignans were recovered in the urine as plant lignans or enterolignans. This is in the same range as previously observed in rats given radiolabelled secoisolariciresinol diglucoside ${ }^{(52)}$, but slightly lower than in human studies with flaxseeds, where approximately $40 \%$ of the ingested secoisolariciresinol diglucoside was excreted as enterolignans in the urine ${ }^{(53)}$. Based on the assumption that the colonic microflora would efficiently deconjugate the majority of lignans, only unconjugated lignans were determined in the faeces ${ }^{(24,54)}$. If present at higher levels than anticipated, conjugated lignans may have contributed to the discrepancy between estimated production and 
measured excretion of enterolignans in the present study. They would also result in lower true faecal digestibility of the plant lignans than the calculated apparent digestibilities presented here. Another minor contribution may be caused by oxidation to other metabolites ${ }^{(43,55,56)}$. Finally, quantitative losses of urine and/or further microbial activity in the collection bottle may contribute to the gap between estimated production and the actual recovery of enterolignans. The lower concentration of lignans in urine collected quantitatively than in the urine collected directly from the bladder is believed mainly to be caused by dilution with drinking water, but may also reflect losses as suggested above.

In contrast to the present study, previous studies have recovered two to ten times more enterolignan in faeces and urine than was expected from the intake of precursors ${ }^{(24,30)}$, the main reason being the incomplete knowledge of the amounts of enterolignan precursors in the diet. Conversion of lignin to lignans is another possible contributor to enterolignan excretion both in the present and previous studies. Previously it was found that lignin accounted for $26-32 \%$ of the ENL production in rats fed rye and wheat bran ${ }^{(57)}$.

Body retention could potentially also contribute to the difference between estimated production and excretion, as enterolignans in the form of ENL were detected in various tissues. However, in the present study accumulation is expected only to parallel the growth of tissue, as a 'steadystate' condition can be expected after continuous ingestion for 9-10 weeks. Peroral exposure to ${ }^{3} \mathrm{H}$-labelled secoisolariciresinol diglycoside from flaxseed in rats has shown that the majority of radioactivity was recovered in the faeces and urine, while of twelve tissues analysed the highest concentrations were found in the liver, kidney and uterus ${ }^{(52)}$. The high concentrations in these tissues after chronic exposure (10d) was argued to be a consequence of the liver being the main site of conjugation with glucuronide, a high concentration of anti-oestrogenic binding sites in the liver, significant renal excretion of lignan metabolites, and the antagonising oestrogen action of enterolignans in the uterus ${ }^{(52)}$. A study in rats fed diets enriched with linseed meal showed doserelated increases of END and ENL in the liver, testes, prostate and lung tissue ${ }^{(58)}$. The present study is to our knowledge the first to demonstrate ENL in various tissues after intake of high amounts of rye. The moderate levels of ENL found in breast tissue and high levels found in plasma could definitely have biological activity. Previously it was shown that ENL accumulates in breast cysts, and that it modulates the risk related to high intracystic levels of epidermal growth factor ${ }^{(59)}$, and it has recently been shown that higher blood concentrations of ENL reduce the risk of breast cancer. While Olsen et al. ${ }^{(60)}$ found an incidence rate ratio of 0.71 per $20 \mathrm{nmol} / 1$ higher plasma ENL associated with oestrogen receptor- $\alpha$-negative tumours, Sonestedt et al. ${ }^{(61)}$ showed that blood concentrations above $16 \mathrm{nmol} / \mathrm{l}$ diminished the risk for breast cancer in oestrogen receptor $\alpha$-positive (OR 0.75 ) and oestrogen receptor $\beta$-negative (OR 0.60) tumours. Hence, ENL appears to modulate oestrogen receptor function, but the protective effect against breast cancer is probably mediated through several other mechanisms and factors related to the food consumed, particularly cereal fibre intake ${ }^{(1,62)}$.

We have previously demonstrated an attenuating effect on plasma total and LDL-cholesterol of the diets in the hypercholesterolaemic pigs used in the present study. Lignans have been proposed to exert a cholesterol-lowering effect by stimulation of the LDL receptor activity ${ }^{(11)}$, although this could not be confirmed by the expression of mRNA in the liver of the pigs from the present study ${ }^{(17)}$. Currently, it is not known to what extent the lignans contribute to the hypocholesterolaemic effect obtained. The protective effect of whole grain against cancers and CVD as seen in some but not all epidemiological studies may be brought about by many mechanisms as discussed in a recent review ${ }^{(1)}$. To what extent the lignans play an essential role by themselves, or are merely biomarkers, is still debated.

\section{Conclusion}

The present study shows that the lignans of rye are interconverted in the intestine and taken up to the systemic circulation to a variable extent. Some lignans are deposited in different tissues, but only ENL at a concentration high enough to be well quantified. At high intake levels, plant lignans are also taken up to the bloodstream and excreted via the urine and particularly via bile. This implies that the enterolignans and their precursors undergo enterohepatic circulation to a variable extent. The present study is to our knowledge the first to show that plant lignans are found in high concentrations in bile. Whether this is a mechanism of systemic elimination awaits further investigation.

\section{Acknowledgements}

H. N. L. was responsible for carrying out the animal experiment and data analysis. H. N. L. drafted the manuscript and is the corresponding author. M. A. M. and M. S. H. participated in conducting the animal experiment. K. E. B. K. was responsible for the project development and contributed with intellectual input to the planning, execution and evaluation of the experiment. J. L. P. and H. A. were responsible for developing and carrying out the lignan analyses. All authors contributed with intellectual input and writing of the manuscript.

Skilful assistance by the technical staff at University of Helsinki, Institute for Preventive Medicine, at Aarhus University, Department of Animal Health, Welfare and Nutrition and Department of Farm and Animal Research Facilities was greatly appreciated.

There are no conflicts of interests.

\section{References}

1. Adlercreutz H (2007) Lignans and human health. Crit Rev Clin Lab Sci 44, 483-525.

2. Pan A, Sun J, Chen Y, et al. (2007) Effects of a flaxseed-derived lignan supplement in type 2 diabetic patients: a randomized, double-blind, cross-over trial. PLOS ONE 2, e1148.

3. Bhathena SJ \& Velasquez MT (2002) Beneficial role of dietary phytoestrogens in obesity and diabetes. Am J Clin Nutr 76, 1191-1201.

4. Jenkins DJ, Kendall CW, Vidgen E, et al. (1999) Health aspects of partially defatted flaxseed, including effects on serum lipids, oxidative measures, and ex vivo androgen and progestin activity: a controlled crossover trial. Am J Clin Nutr 69, 395-402. 
5. Leinonen KS, Poutanen KS \& Mykkanen HM (2000) Rye bread decreases serum total and LDL cholesterol in men with moderately elevated serum cholesterol. J Nutr 130, 164-170.

6. Vanharanta M, Voutilainen S, Rissanen TH, et al. (2003) Risk of cardiovascular disease-related and all-cause death according to serum concentrations of enterolactone - Kuopio Ischaemic Heart Disease Risk Factor Study. Arch Intern Med 163, 1099-1104.

7. van der Schouw YT, Pijpe A, Lebrun CEI, et al. (2002) Higher usual dietary intake of phytoestrogens is associated with lower aortic stiffness in postmenopausal women. Arterioscler Thromb Vasc Biol 22, 1316-1322.

8. de Kleijn MJJ, van der Schouw YT, Wilson PWF, et al. (2002) Dietary intake of phytoestrogens is associated with a favorable metabolic cardiovascular risk profile in postmenopausal US women: The Framingham Study. J Nutr 132, 276-282.

9. Kitts DD, Yuan YV, Wijewickreme AN, et al. (1999) Antioxidant activity of the flaxseed lignan secoisolariciresinol diglycoside and its mammalian lignan metabolites enterodiol and enterolactone. Mol Cell Biochem 202, 91-100.

10. Vanharanta M, Voutilainen S, Lakka TA, et al. (1999) Risk of acute coronary events according to serum concentrations of enterolactone: a prospective population-based case-control study. Lancet 354, 2112-2115.

11. Owen AJ, Roach PD \& Abbey M (2004) Regulation of low-density lipoprotein receptor activity by estrogens and phytoestrogens in a HepG2 cell model. Ann Nutr Metab 48, 269-275.

12. Sanghvi A, Diven WF, Seltman H, et al. (1985) Inhibition of rat-liver cholesterol 7- $\alpha$-hydroxylase and acyl-CoA; cholesterol acyl transferase activities by enterodiol and enterolactone. $A d v$ Exp Med Biol 183, 450.

13. Lee CC, Chen PR, Lin S, et al. (2004) Sesamin induces nitric oxide and decreases endothelin-1 production in HUVECs: possible implications for its anti hypertensive effect. J Hypertens 22, 2329-2338.

14. Heinonen $\mathrm{S}$, Nurmi $\mathrm{T}$, Liukkonen $\mathrm{K}$, et al. (2001) In vitro metabolism of plant lignans: new precursors of mammalian lignans enterolactone and enterodiol. J Agric Food Chem 49, 3178-3186.

15. Penalvo JL \& Nurmi T (2006) Application of coulometric electrode array detection to the analysis of isoflavonoids and lignans. J Pharm Biomed Anal 41, 1497-1507.

16. Smeds AI, Eklund PC, Sjoholm RE, et al. (2007) Quantification of a broad spectrum of lignans in cereals, oilseeds, and nuts. J Agric Food Chem 55, 1337-1346.

17. Lærke HN, Pedersen C, Mortensen MA, et al. (2008) Rye bread reduces plasma cholesterol levels in hypercholesterolaemic pigs when compared to wheat at similar dietary fibre level. $J$ Sci Food Agric 88, 1385-1393.

18. Schürch AF, Lloyd LE \& Crampton EW (1950) The use of chromic oxide as an index for determining the digestibility of a diet. J Nutr 50, 629-636.

19. Penalvo JL, Haajanen KM, Botting N, et al. (2005) Quantification of lignans in food using isotope dilution gas chromatography/mass spectrometry. J Agric Food Chem 53, 9342-9347.

20. Nurmi T, Voutilainen S, Nyyssonen K, et al. (2003) Liquid chromatography method for plant and mammalian lignans in human urine. J Chromatogr B Analyt Technol Biomed Life Sci 798, $101-110$.

21. Penalvo JL, Nurmi T, Haajanen K, et al. (2004) Determination of lignans in human plasma by liquid chromatography with coulometric electrode array detection. Anal Biochem 332, 384-393.

22. Littell RC, Milliken GA, Stroup WW, et al. (1996) SAS System for Mixed Models. Cary, NC: SAS Institute Inc.

23. Nilsson M, Aman P, Harkonen H, et al. (1997) Content of nutrients and lignans in roller milled fractions of rye. J Sci Food Agric 73, 143-148.

24. Glitso LV, Mazur WM, Adlercreutz H, et al. (2000) Intestinal metabolism of rye lignans in pigs. Br J Nutr 84, 429-437.
25. Milder IEJ, Arts ICW, van de Putte B, et al. (2005) Lignan contents of Dutch plant foods: a database including lariciresinol, pinoresinol, secoisolariciresinol and matairesinol. Br J Nutr 93, 393-402.

26. Hedelin M, Klint A, Chang ET, et al. (2006) Dietary phytoestrogen, serum enterolactone and risk of prostate cancer: the Cancer Prostate Sweden Study (Sweden). Cancer Causes Control 17, 169-180.

27. Bach Knudsen KE, Serena A, Kjaer AK, et al. (2003) Rye bread in the diet of pigs enhances the formation of enterolactone and increases its levels in plasma, urine and feces. J Nutr 133, $1368-1375$.

28. Adlercreutz H, Fotsis T, Lampe J, et al. (1993) Quantitative determination of lignans and isoflavonoids in plasma of omnivorous and vegetarian women by isotope dilution gas chromatography mass-spectrometry. Scand J Clin Lab Invest 53, 5-18.

29. Adlercreutz H, Fotsis T, Kurzer MS, et al. (1995) Isotope dilution gas chromatographic mass-spectrometric method for the determination of unconjugated lignans and isoflavonoids in human feces, with preliminary results in omnivorous and vegetarian women. Anal Biochem 225, 101-108.

30. Juntunen KS, Mazur WM, Liukkonen KH, et al. (2000) Consumption of wholemeal rye bread increases serum concentrations and urinary excretion of enterolactone compared with consumption of white wheat bread in healthy Finnish men and women. Br J Nutr 84, 839-846.

31. Jacobs DR, Pereira MA, Stumpf K, et al. (2002) Whole grain food intake elevates serum enterolactone. $B r J$ Nutr 88, 111-116.

32. Vanharanta M, Voutilainen S, Nurmi T, et al. (2002) Association between low serum enterolactone and increased plasma F-2-isoprostanes, a measure of lipid peroxidation. Atherosclerosis 160, 465-469.

33. McIntosh GH, Noakes M, Royle PJ, et al. (2003) Whole-grain rye and wheat foods and markers of bowel health in overweight middle-aged men. Am J Clin Nutr 77, 967-974.

34. Kilkkinen A, Stumpf K, Pietinen P, et al. (2001) Determinants of serum enterolactone concentration. Am J Clin Nutr 73, 1094-1100.

35. Horner NK, Kristal AR, Prunty J, et al. (2002) Dietary determinants of plasma enterolactone. Cancer Epidemiol Biomarkers Prev 11, 121-126.

36. Johnsen NF, Hausner H, Olsen A, et al. (2004) Intake of whole grains and vegetables determines the plasma enterolactone concentration of Danish women. J Nutr 134, 2691-2697.

37. Niemeyer HB, Honig DM, Kulling SE, et al. (2003) Studies on the metabolism of the plant lignans secoisolariciresinol and matairesinol. J Agric Food Chem 51, 6317-6325.

38. Nose M, Fujimoto T, Nishibe S, et al. (1993) Structural transformation of lignan compounds in rat gastrointestinal tract. 2 . Serum concentration of lignans and their metabolites. Planta Med 59, 131-134.

39. Niemeyer HB, Honig D, Lange-Bohmer A, et al. (2000) Oxidative metabolites of the mammalian lignans enterodiol and enterolactone in rat bile and urine. J Agric Food Chem 48, 2910-2919.

40. Millburn P, Smith RL \& Williams RT (1967) Biliary excretion of foreign compounds. Biphenyl, stilboestrol and phenolphthalein in the rat: molecular weight, polarity and metabolism as factors in biliary excretion. Biochem J 105, 1275-1281.

41. Aubertin-Leheudre M, Gorbach S, Woods M, et al. (2008) Fat/fiber intakes and sex hormones in healthy premenopausal women in USA. J Steroid Biochem Mol Biol 112, 32-39.

42. Piller R, Verla-Tebit E, Wang-Gohrke S, et al. (2006) CYP17 genotype modifies the association between lignan supply and premenopausal breast cancer risk in humans. J Nutr 136, $1596-1603$. 
43. Niemeyer HB \& Metzler M (2003) Differences in the antioxidant activity of plant and mammalian lignans. J Food Eng 56, 255-256.

44. Prasad K (2005) Hypocholesterolemic and anti atherosclerotic effect of flax lignan complex isolated from flaxseed. Atherosclerosis 179, 269-275.

45. Pool-Zobel BL, Adlercreutz H, Glei M, et al. (2000) Isoflavonoids and lignans have different potentials to modulate oxidative genetic damage in human colon cells. Carcinogenesis 21, 1247-1252.

46. Harder H, Tetens I, Let MB, et al. (2004) Rye bran bread intake elevates urinary excretion of ferulic acid in humans, but does not affect the susceptibility of LDL to oxidation ex vivo. Eur J Nutr 43, 230-236.

47. Woodside JV, Morton MS, Cooper A, et al. (2006) Short-term consumption of phytoestrogen-rich foods in humans alters dietary macro- and micronutrient intake. Nutr Res 26, 7-10.

48. Hallund J, Ravn-Haren G, Bugel S, et al. (2006) A lignan complex isolated from flaxseed does not affect plasma lipid concentrations or antioxidant capacity in healthy postmenopausal women. $J$ Nutr 136, 112-116.

49. Nesbitt PD, Lam Y \& Thompson LU (1999) Human metabolism of mammalian lignan precursors in raw and processed flaxseed. Am J Clin Nutr 69, 549-555.

50. Hutchins AM, Martini MC, Olson BA, et al. (2000) Flaxseed influences urinary lignan excretion in a dose-dependent manner in postmenopausal women. Cancer Epidemiol Biomarkers Prev 9, 1113-1118.

51. Smeds AI, Saarinen NM, Hurmerinta TT, et al. (2004) Urinary excretion of lignans after administration of isolated plant lignans to rats: the effect of single dose and ten-day exposures. J Chromatogr B 813, 303-312.

52. Rickard SE \& Thompson LU (1998) Chronic exposure to secoisolariciresinol diglycoside alters lignan disposition in rats. $J$ Nutr 128, 615-623.
53. Kuijsten A, Arts JCW, Vree TB, et al. (2005) Pharmacokinetics of enterolignans in healthy men and women consuming a single dose of secoisolariciresinol diglucoside. J Nutr 135, 795-801.

54. Adlercreutz H, Fotsis T, Kurzer MS, et al. (1995) Isotope dilution gas chromatographic-mass spectrometric method for the determination of unconjugated lignans and isoflavonoids in human feces, with preliminary results in omnivorous and vegetarian women. Anal Biochem 225, 101-108.

55. Jacobs E, Kulling SE \& Metzler M (1999) Novel metabolites of the mammalian lignans enterolactone and enterodiol in human urine. J Steroid Biochem Mol Biol 68, 211-218.

56. Smeds AI, Saarinen NM, Eklund PC, et al. (2005) New lignan metabolites in rat urine. J Chromatogr B 816, 87-97.

57. Begum AN, Nicolle C, Mila I, et al. (2004) Dietary lignins are precursors of mammalian lignans in rats. J Nutr 134, 120-127.

58. Murray T, Kang J, Astheimer L, et al. (2007) Tissue distribution of lignans in rats in response to diet, dose-response, and competition with isoflavones. J Agric Food Chem 55, 4907-4912.

59. Boccardo F, Lunardi GL, Petti AR, et al. (2003) Enterolactone in breast cyst fluid: correlation with EGF and breast cancer risk. Breast Cancer Res Treat 79, 17-23.

60. Olsen A, Knudsen KEB, Thomsen BL, et al. (2004) Plasma enterolactone and breast cancer incidence by estrogen receptor status. Cancer Epidemiol Biomarkers Prev 13, 2084-2089.

61. Sonestedt E, Borgquist S, Ericson U, et al. (2008) Enterolactone is differently associated with estrogen receptor $\beta$-negative and -positive breast cancer in a Swedish Nested Case-Control Study. Cancer Epidemiol Biomarkers Prev 17, 3241-3251.

62. Suzuki R, Rylander-Rudqvist T, Ye W, et al. (2008) Dietary fiber intake and risk of postmenopausal breast cancer defined by estrogen and progesterone receptor status - a prospective cohort study among Swedish women. Int $J$ Cancer 122, 403-412. 